\title{
Optimal dynamic water allocation: Irrigation extractions and environmental tradeoffs in the Murray River, Australia
}

\author{
R. Quentin Grafton, ${ }^{1}$ Hoang Long Chu, ${ }^{1}$ Michael Stewardson, ${ }^{2}$ and Tom Kompas ${ }^{1}$ \\ Received 25 July 2010; revised 22 November 2010; accepted 8 February 2011; published 30 June 2011.
}

[1] A key challenge in managing semiarid basins, such as in the Murray-Darling in Australia, is to balance the trade-offs between the net benefits of allocating water for irrigated agriculture, and other uses, versus the costs of reduced surface flows for the environment. Typically, water planners do not have the tools to optimally and dynamically allocate water among competing uses. We address this problem by developing a general stochastic, dynamic programming model with four state variables (the drought status, the current weather, weather correlation, and current storage) and two controls (environmental release and irrigation allocation) to optimally allocate water between extractions and in situ uses. The model is calibrated to Australia's Murray River that generates: (1) a robust qualitative result that "pulse" or artificial flood events are an optimal way to deliver environmental flows over and above conveyance of base flows; (2) from 2001 to 2009 a water reallocation that would have given less to irrigated agriculture and more to environmental flows would have generated between half a billion and over 3 billion U.S. dollars in overall economic benefits; and (3) water markets increase optimal environmental releases by reducing the losses associated with reduced water diversions.

Citation: Grafton, R. Q., H. L. Chu, M. Stewardson, and T. Kompas (2011), Optimal dynamic water allocation: Irrigation extractions and environmental tradeoffs in the Murray River, Australia, Water Resour. Res., 47, W00G08, doi:10.1029/2010WR009786.

\section{Introduction}

[2] Over half of the global accessible runoff is appropriated for human purposes [Postel et al., 1996] and some $80 \%$ of freshwater used by humans is extracted for irrigation purposes [Thenkabail et al., 2009]. In semiarid regions, such as Australia's Murray-Darling Basin, irrigation is of particular importance and can increase the value of agricultural production severalfold relative to that of dry-land cultivation. For example, irrigated agriculture in Australia generates $28 \%$ of the value of agricultural production from only $1 \%$ of its agricultural land area [Meyer, 2005].

[3] While water for irrigation generates substantial benefits, extractions also have the potential to generate environmental costs because they alter both the volume and variability of river flow [Bunn and Arthington, 2002; Dudgeon et al., 2006; Poff et al., 2007, 2010]. This is a concern because globally the area of land devoted to irrigation has expanded from 280 to over 400 million ha in the past three decades [Thenkabail et al., 2009]. Much of the surface water supplied to irrigated agriculture is stored, at some point in time, in the world's more than 45,000 large dams that are capable of holding up to $15 \%$ of the total global surface runoff [Nilsson et al., 2005].

\footnotetext{
${ }^{1}$ Crawford School of Economics and Government, Australian National University, Acton, ACT, Australia.

${ }^{2}$ Department of Civil and Environmental Engineering, University of Melbourne, Melbourne, Victoria, Australia.
}

Copyright 2011 by the American Geophysical Union. 0043-1397/11/2010WR009786
[4] Water regulation for irrigation is a particular challenge in the Murray-Darling Basin, Australia. This is because dam storage capacity exceeds the mean annual runoff and system outflows have been reduced to a fraction of their predevelopment levels. Much of this development has occurred in the recent past as water diversions in Australian rivers increased by over 50\% between 1985-1986 and 1995-1996 [National Land and Water Resources Audit, 2001]. Water storages smooth river flows and provide a secure supply of water for irrigation when required, especially over summer months. As a result of this regulation, peak flows associated with flooding events have diminished in both size and frequency, and median annual flows out to sea in the basin are now less than $30 \%$ of their natural levels [Commonwealth Scientific and Industrial Research Organisation (CSIRO), 2008].

[5] The nature of water regulation in the southern Murray-Darling Basin is that many existing water resource plans allow for water diversions for irrigated agriculture to be reduced by a smaller proportion than inflows during lowinflow periods. As a result, on the Murray River the water diverted for irrigation has increased from less than half in the 1980 s and 1990 s to over $75 \%$ in the past decade-long drought [Grafton and Jiang, 2010]. Reduced environmental flows have contributed to widespread degradation along the Murray River with $95 \%$ of the floodplain trees on its lower reaches either degraded or dying [Murray-Darling Basin Commission (MDBC), 2003]. Norris [2010, pp. 23-24] has summarized the key environmental assessments in the basin over the past decade and observed there is clear evidence of poor ecological conditions in many of its rivers. Before the current drought, Norris et al. [2001] concluded that $40 \%$ of the river length assessed had a degraded environmental 
condition. At the end of the system there is high salinity, exposed acid-sulfate soils that generate water acidity that can result in fish die offs, and virtually no flows at the Murray Mouth over the past decade [Senate Standing Committee on Rural and Regional Affairs and Transport, 2008].

[6] In response to the evidence of degraded habitats, scientists have argued for increased environmental flows [Poff et al., 1997; Richter et al., 1997; Arthington et al., 2010; Poff et al., 2010]. The problem for policy makers and water planners is that allocating more water for the environment means less water for irrigated agriculture. To help decision makers respond to this dilemma and to better understand the trade-offs, we develop an optimal and dynamic water allocation model. As far as we are aware, it is the first dynamic and stochastic water model that accounts for the key states of the environment and correlated weather events that can be used to economically optimize water allocations for diversions versus in situ uses.

[7] We calibrate the optimal dynamic water allocation model to the Murray River of Australia, but it could be applied generally to any river system where there are tradeoffs between diversions (agricultural, industrial, or domestic) and environmental flows coupled with adequate data on flows and benefits of alternative uses. Recent work has produced global data sets of irrigated land area [Thenkabail et al., 2009], large dams [Nilsson et al., 2005], and freshwater ecosystems [Lehner and Döll, 2004] plus a capacity to model human and climate change impacts on continental and global water systems [Lehner et al., 2006; Haddeland et al., 2007; Dai et al., 2009; Döll et al., 2009]. These data and tools make it possible to use our modeling approach to examine the sustainability of marginal adjustments in the timing and location of water delivered for agricultural production. By contrast to existing methods that are local scale and idiosyncratic, our optimal dynamic water allocation model is a general analytical approach capable of quantifying the economic trade-offs between the environment and extractive uses at a basin scale. The underlying parameters of the model can be adapted to particular catchments where there is additional information on the hydrology and ecology. Sensitivity of the results in terms of net gains (dollars) and water allocations can then be assessed under alternative scenarios in terms of climate, the environment, and net benefits of use.

[8] The dynamic model is constructed with four state variables: the current weather, the weather correlation, the current water storage available for allocation, and the status of droughts (if any). At any point in time, given the four states and any serial correlation in the weather, the water planner determines the two control variables: environmental water releases from storages and permitted irrigation extractions. The quantity of water saved for future use is the unallocated inflow into the system and is neither allocated to irrigators, nor is it released to the environment in the current period, but is stored in dams for later use.

[9] The model is to maximize the net present value of water from allocating it between competing uses. In other words, it maximizes the discounted net present value of the expected benefits of water in (1) irrigated agriculture, (2) environmental releases, and (3) future uses in terms of both extractions and in situ uses by specifying an optimal action contingent on the information available at any points in time using the Principle of Optimality [Bellman, 1957]. The model is calibrated to the Murray River to show the difference between actual and optimal water allocations and the estimated net gain in dollar terms. While the specific optimal irrigation volume and environmental releases are sensitive to particular parameter values, the model does generate a qualitatively robust result, namely, that artificial floods or "pulse" effects [Junk et al., 1989] are needed to avoid excessive environmental costs associated with droughts.

[10] Section 2 describes how the relationships among variables are modeled. Section 3 briefly describes the Murray region and its river system, and the baseline numerical parameters used in terms of calibration and application. Section 4 presents the key model results and compares actual versus optimal water allocations over the period 2001-2009 along with a sensitivity analysis of the results to changes in the base-case parameter values. Section 5 offers a brief discussion and conclusions.

\section{Model Description}

\subsection{Modeling Weather, Weather Serial Correlation, and Climate Trend}

[11] The model includes three types of weather: dry, normal, and wet (indexed by $d, n$, and $w$ ). This allows us to account for serial correlation in weather when setting current water allocations; we specify that the weather type in each year is a random variable, but correlated with the weather in the two previous years. Thus, the weather last year (denoted as $P$ ) and this year (denoted as $W$ ), can directly influence the probability of the next year's weather. (Conventionally, we use capital Latin letters for state variables, Greek letters for parameters, and lowercase letters for control variables or functional notations.) The weather further in the past affects the weather next year indirectly via the weather in the previous two years.

[12] Table 1 represents a hypothetical relationship between weather over different years. The $(d, d)$ cell in the first matrix represents the probability of dry weather in the following period $(60 \%)$ given that the previous and current period were both dry. The $(d, n)$ cell indicates that if the current weather is normal and last year's weather was dry, the probability of dry weather in the following period is only $30 \%$. If the weather was normal this year and also last year, then the $(n, n)$ cell indicates that the probability of dry weather next year would be only $15 \%$. The second and third matrices have similar interpretations except they refer, respectively, to the probability of normal weather and wet weather occurring next year. The probabilities given in the identically located cells in each matrix sum to 1.0.

[13] The hypothetical probabilities in Table 1 indicate that (1) the climate trend is neutral because the probabilities of the two extremes, dry and wet weather, are symmetric and (2) the correlation becomes weaker if the two years are further apart such that the current weather has a bigger effect on the probability of next year's weather than last year's weather. A climate trend, such as a drought, can be incorporated into the weather if the probabilities are asymmetric. The transition of the weather type from the current year $(W)$ to the following period is probabilistic as the weather type in the next year is not yet realized. The only 
Table 1. Hypothetical Serial Correlation of Weather Periods

\begin{tabular}{|c|c|c|c|c|c|c|c|c|c|c|c|}
\hline \multicolumn{4}{|c|}{$\begin{array}{l}\text { Probability of Dry Weather Next Year, } \\
\qquad W_{t+1}=d\end{array}$} & \multicolumn{4}{|c|}{$\begin{array}{l}\text { Probability of Normal Weather Next Year, } \\
\qquad W_{t+1}=n\end{array}$} & \multicolumn{4}{|c|}{$\begin{array}{l}\text { Probability of Wet Weather Next Year, } \\
\qquad W_{t+1}=w\end{array}$} \\
\hline$W$ & $P=d$ & $P=n$ & $P=w$ & $W$ & $P=d$ & $P=n$ & $P=w$ & $W$ & $P=d$ & $P=n$ & $P=w$ \\
\hline$d$ & 0.6 & 0.5 & 0.4 & $d$ & 0.3 & 0.3 & 0.4 & $d$ & 0.1 & 0.2 & 0.2 \\
\hline$n$ & 0.3 & 0.15 & 0.2 & $n$ & 0.5 & 0.7 & 0.5 & $n$ & 0.2 & 0.15 & 0.3 \\
\hline$w$ & 0.2 & 0.2 & 0.1 & $w$ & 0.4 & 0.3 & 0.3 & $w$ & 0.4 & 0.5 & 0.6 \\
\hline
\end{tabular}

information we have about the transition law of $W$ is the uncontrolled probability distribution described as

$$
\begin{aligned}
& P_{t+1}=W_{t}, \\
& W_{t+1}=\left\{\begin{array}{l}
d \text { if the next period weather is dry, } \\
n \text { if the next period weather is normal } \\
w \text { if the next period weather is wet. }
\end{array}\right.
\end{aligned}
$$

[14] This probability distribution is important as it helps determine the current water allocation. The total water availability each year, measured as summed inflows over the basin inflow points, also depends on the weather type, and hence, itself is a random variable. If we use the weather type as subscripts, then the water availability can be represented by a three-element vector $\Phi=\left\{\Phi^{d}, \Phi^{n}, \Phi^{w}\right\}$, where $\Phi^{d}<\Phi^{n}<\Phi^{w}$.

\subsection{Water Balance Calculation}

[15] All river systems that have water extractions require a minimum amount of water to convey allocations from upstream to downstream locations. This water can be called conveyance water and is a "fixed cost" in terms of the water required to meet irrigation requirements. We denote this amount, net of evaporation associated with the conveyance of water along the river, as a fixed quantity $\delta$. The mass conservation condition relating the three uses of water (irrigation, environment, and future allocation) is

$$
\Delta R+(e+i)=\Phi-\delta-\eta R
$$

or after rearranging and with time subscripts it can be written as follows:

$$
R_{t+1}=\left(\Phi_{t}-\delta\right)-\left(e_{t}+i_{t}\right)-\eta R_{t}+R_{t}
$$

where $\Delta R$ is the change in the water storage, $R$ is current storage, $e$ are planned environmental releases, $i$ is irrigation extractions, and $\eta$ is the evaporation rate in water storages. (We specify evaporation as fixed proportion of volumes in the general setup of the model. When calibrating the model at a catchment level evaporation should account for various factors including surface area of water storages, temperature, wind, etc.) However, the storage, at any points in time, is always bounded from above by the maximum storage capacity that is denoted by $\bar{R}$. If the inflow in a year is too large, water will be spilled out of storage facilities. Therefore, the transition of the water storage in equation (2) is modified in equation (3) to capture the maximum storage capacity:

$$
R_{t+1}=\min \left[\left(\Phi_{t}-\delta\right)-\left(e_{t}+i_{t}\right)-\eta R_{t}+R_{t}, \bar{R}\right] .
$$

\subsection{Flood Intensities, Flood Break Periods, and Environment Water Intake}

[16] Floods with different intensities have different impacts on the environment, where intensity refers to both the volume and duration of flows. Bigger floods inundate higher floodplain surfaces and wetlands more distant from the river channel. They also deliver larger volumes of water onto the floodplain and can extend the period of time before rewetting is required. A smaller flood applies water to lower and nearer floodplains. Our model simplifies the environmental requirements by defining the periods required between floods as a "break period" (denoted as $\Pi$ ).

[17] Floods are classified into big, medium, and small types (indexed as $b, m$, and $s$ ) with different break periods $\left(\Pi_{b}>\Pi_{m}>\Pi_{s} \geq 0\right)$. A simplification in the model is that smaller floods have shorter break periods. Thus, the intensity of a flood depends on whether the minimum thresholds (denoted as $\Delta_{b}, \Delta_{m}$, and $\Delta_{s}$ with $\Delta_{b}>\Delta_{m}>\Delta_{s}>0$ ) that trigger each type of flood are exceeded by the environment water intake. (We differentiate between conveyance water and environment water intake. Conveyance water that contains unregulated inflow may contribute to floods (or even provide some environmental benefit). However, as we assume a fixed conveyance, all environmental effects of the conveyance are considered to be "sunk.") There are two sources of the environment water intake, namely environment releases $(e)$ and the spill water $(f)$ arising after the storage is completely full by inflows. (A certain proportion of irrigation water returns to the environment as specified in CSIRO [2007] and may have some ecological benefits. However, as irrigation demands are spread through time in a year, water returning from irrigation generates few benefits and does not contribute to floods. Thus, water diversions for irrigated agriculture may be viewed as "lost" to the river environment [Kingsford, 2010, p. 11].) The break period, which is determined by the flood intensity, can be represented by

$$
\Pi=\left\{\begin{array}{l}
\Pi_{b} \text { if big floods: } e+f \geq \Delta_{b}, \\
\Pi_{m} \text { if medium floods: } e+f \in\left[\Delta_{m}, \Delta_{b}\right), \\
\Pi_{s} \text { if small floods: } e+f \in\left[\Delta_{s}, \Delta_{m}\right)
\end{array}\right.
$$

where the spill water $f$ arises only when the inflow $\left(\Phi_{t}\right)$, netting evaporation along the rivers and at storage facility $\left(\delta+\eta R_{t}\right)$, and the irrigation and environmental volumes $\left(i_{t}\right.$ $\left.+e_{t}\right)$ combined with the current storage, exceeds the maximum storage capacity $\bar{R}$. Therefore, the spill water $f$ can be calculated as

$$
f=\max \left\{\left[\Phi_{t}-\left(\delta+\eta R_{t}\right)-(e+i)\right]+R_{t}-\bar{R}, 0\right\} .
$$




\subsection{Interflood Period and Drought Length}

[18] An interflood period is defined as the time between two flood events and, thus, it begins and ends with a flood. A drought is defined as commencing when the interflood period exceeds the break period. In other words, an interflood period is divided into two intervals: (1) a break period where wetting is recent enough that desiccation of the floodplain has not produced substantial environmental costs, and (2) a period after the break period when drought costs to the environment are incurred and before the next flood.

[19] To capture the break times and the damaging droughts, we use a state variable $L$ which can have both negative and positive values. A negative value implies that the environment is still in the break time of the previous flood. A positive value shows how many periods have elapsed since the end of the previous break time, or the length of a damaging drought. When a flood occurs, this state variable becomes negative, implying the start of a flood break time. When two floods are close to each in time, the larger break period will dominate. The transition of this state variable is given by

$$
L_{t+1}=\left\{\begin{array}{l}
-\Pi_{b} \text { if big flood } \\
\min \left(L_{t},-\Pi_{m}\right) \text { if medium flood } \\
\min \left(L_{t},-\Pi_{s}\right) \text { if small flood } \\
L_{t}+1 \text { if no flood. }
\end{array}\right.
$$

\subsection{Drought Cost, Irrigation Profit, and Social Return}

[20] The environmental impact of an extended interflood period is expressed as a "drought cost" that depends on the length of a damaging drought. After a flood, the drought cost remains zero during the break time (when $L \leq 0$ ) before starting to rise exponentially. Thus, the drought cost can be represented by the following:

$$
c_{d}(L)=\alpha \times[\max (L, 0)]^{\beta},
$$

where $\alpha>0$ is the drought cost coefficient and $\beta$ is the drought cost elasticity. We assume $\beta>1.0$ such that the drought cost is an increasing and convex function with respect to the drought length. In other words, as a drought lasts longer, the drought cost will increase at an increasing

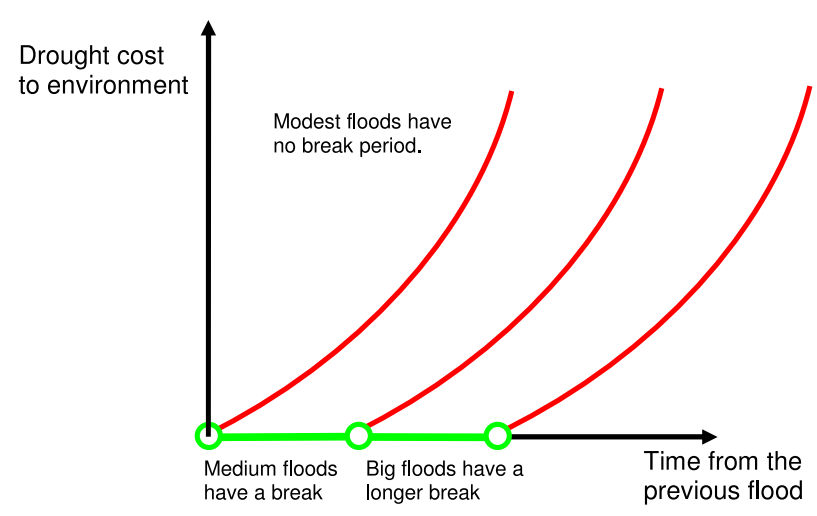

Figure 1. Hypothetical drought costs to the environment. rate. Figure 1 presents an illustration of hypothetical drought costs and break periods.

[21] The initial break period carries no "cost" reflecting adaptation of freshwater biota to natural dry periods between floods. As the interflood period is extended beyond the natural duration a cost is incurred, related, for example, to reduced quantities of carbon and nutrients delivered to the river from the floodplain [Baldwin, 1999; Wilson et al., 2010], or a lack of flood events to trigger water bird breeding events [Kingsford and Auld, 2005]. The exponential increase in cost with longer interflood periods represents the variable threshold effects in some ecological responses. For example, potential threshold effects relate to the role of flooding as a trigger for flood recruitment of fish [Harris and Gehrke, 1994], emergence of microinvertebrates from floodplain soils [Jenkins and Boulton, 1998], and regeneration of riparian forests [Bacon et al., 1993]. Although not represented in the model, there is a maximum cost with drought that would occur when the floodplains have lost all of their environmental value as a freshwater ecosystem.

[22] The net benefits from irrigation are defined as irrigation net profit. We define the inverse demand function for irrigation water as the constant-elasticity form $p(i)=$ $\gamma i^{-\varepsilon}$. The term $p($.$) is the inverse demand function of irri-$ gation water, $\varepsilon \in(0,1)$ is the price elasticity, and $\gamma$ is a parameter. Net profit from water used by irrigated agriculture is illustrated in Figure 2 and defined by the following integral:

$$
\pi_{I}(i)=\int_{0}^{i} p(s) d s-p(i) \times i=\frac{\varepsilon \gamma}{1-\varepsilon} i^{1-\varepsilon} .
$$

[23] Provided the price elasticity lies between 0 and 1, the net profit from the water used in irrigated agriculture is a concave function with respect to the irrigation volume. In other words, an increase in the irrigation volume will raise the irrigation net profit, but at a decreasing rate. This is because irrigation water will first be used for crops where the difference in net profit between dry land and irrigated production is greatest while subsequent irrigation uses of water would generate lower net profit. Thus, when there are reductions in water extractions to irrigated agriculture, the least profitable irrigation activities with the lowest marginal

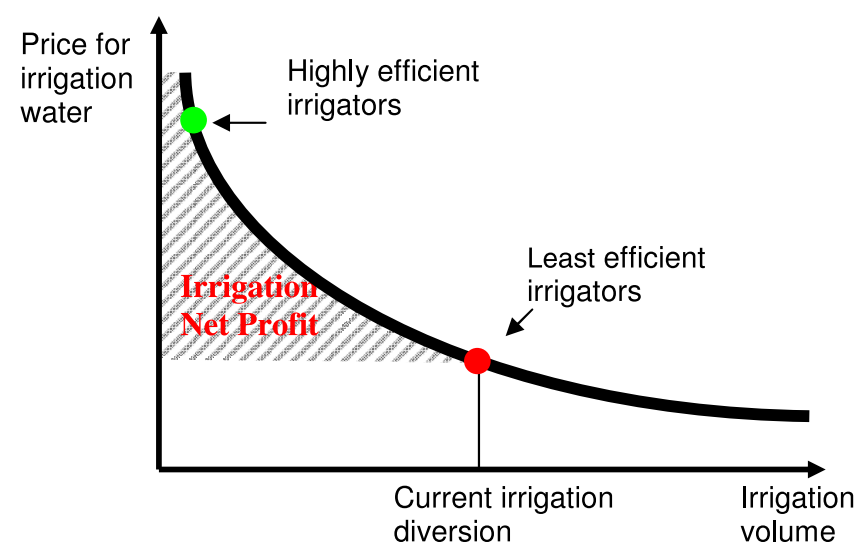

Figure 2. Hypothetical net profit from irrigated agriculture and water diversions. 
net benefit would give up their water first and prior to irrigators with a higher marginal net benefit. We can now define a "social return function" from a given water allocation as per equation (9), which is the net irrigation profit defined in equation (8) net the drought cost defined in equation (7):

$$
\pi(L, e, i)=\frac{\varepsilon \gamma}{1-\varepsilon} i^{1-\varepsilon}-\alpha \times[\max (L, 0)]^{\beta} .
$$

\subsection{Optimal Allocation Strategy and Dynamic Programming Equation}

[24] The optimal water allocation takes into account the current weather, serial correlation in weather across years, the drought length, and disposable water (storage plus inflows) at the beginning of each year. The environment releases and permitted irrigation extractions are determined to maximize the expected net present value of the return described in equation (9). Mathematically, the problem is

$$
\max _{<e_{t}+i_{t} \leq \Phi_{t}+R_{t}>} E_{0} \sum_{t=0}^{\infty}\left(\frac{1}{1+\rho}\right)^{t} \pi\left(L_{t}, e_{t}, i_{t}\right)
$$

subject to the initial values of all state variables and the transition laws described in equations (1), (3), and (6). The Bellman equation for this problem is

$$
\begin{aligned}
V\left(P_{t}, W_{t}, L_{t}, R_{t}\right)= & \max _{\langle e, i\rangle}\left[\pi\left(L_{t}, e_{t}, i_{t}\right)\right. \\
& \left.+\frac{1}{1+\rho} E V\left(P_{t+1}, W_{t+1}, L_{t+1}, R_{t+1}\right)\right]
\end{aligned}
$$

[25] The Bellman equation (11) reflects the Principle of Optimality in the context of dynamic water planning problem. It implies that, at any points in time, the optimal irrigation allocation $(i)$ and environmental release $(e)$ are chosen to maximize the current social return defined in equation (9) plus the discounted value of the expected benefit from the next period onward. These two control variables are chosen contingent on the four state variables, namely, the current weather realization, the past weather realization, the drought length, and the water in storage.

\section{Model Calibration to the Murray Region}

\subsection{Overview of the Murray Region}

[26] The model is applied to the Murray River region of Australia. It extends from the upper reaches of the river to its mouth and encompasses over a half million ha of irrigated cropping land and 600,000 ha of floodplains including internationally recognized wetlands [Kingsford, 2010; Overton et al., 2010]. The Murray River is highly regulated such that the flow through its mouth has been reduced by over $60 \%$, and the periods of no flow have increased in frequency from about $1 \%$ to $40 \%$ of the time [CSIRO, 2008]. The frequency of medium and small floods has been severely reduced [Lintermans, 2007] and resulted in substantial declines in its riparian forests [Overton et al., 2010].

[27] To operationalize the model, we use the units of billion U.S. dollars (USDs) for monetary variables and teraliters (TL) for water volumes and 2001 as the baseline year. For the baseline scenario, we take the price elasticity $\varepsilon \approx 0.85$ from Grafton and Jiang [2010], who estimate that a $10 \%$ reduction in irrigation volume results in a $1.59 \%$ reduction in annual net irrigation profits. This price elasticity is similar to Scoccimarro and Collins [2006] and Brennan [2004]. Substituting the irrigation volume and profit in the base year 2001 into equation (8) (the irrigation volume is $4.14 \mathrm{TL}$ and irrigation net profit is USD 1.62 billion [Grafton and Jiang, 2010]), we calculate $\gamma=0.2647$.

[28] To calculate the drought cost parameters $(\alpha, \beta)$, we rely on an assumption of "half-depletion time" (denoted as $a$ ) and "full-depletion time" (denoted as $b$ ). The halfdepletion time is the length of a drought that makes the cumulative present value of the drought cost equal to $50 \%$ of the irrigation net profits over the same period of time. Likewise, the full-depletion time is the length of a drought that makes the cumulative present value of the drought cost equal to $100 \%$ of the irrigation net profits. For the baseline scenario, we specify a "pro-irrigation" set of parameters such that the half-depletion time is $a=20$ years and the full-depletion time is $b=30$ years. Given these assumptions, and assuming the discount rate $\rho=0.05$, the drought cost coefficient and elasticity can be directly calculated and are given by $(\alpha, \beta)=(0.0037$, 2.1). A comparison of the results under different values of the half-depletion time and full-depletion time is also provided.

\subsection{Hydrological Parameters and Weather Correlation}

[29] The arithmetic mean of total water inflows associated with the three types of weather are estimated using monthly total inflow data for the period May 1891 to April 2006. The monthly data is aggregated into annual data for July-June years. There are multiple irrigation supply reservoirs located both on the Murray River and its tributaries, with the Goulburn and Murrumbidgee rivers delivering greatest inflows. In addition, the Snowy Mountain scheme diverts water into the Murray River Basin from the adjacent Snowy River Basin.

[30] The model represents the water supply system as a single annual input to a single "virtual" reservoir with storage capacity equal to the sum of major reservoirs storage capacities within the Murray catchment. This simplification is required to examine basin-scale trade-off decisions between environmental and irrigation water use. Scenario analysis using detailed representation of the water supply system based on shorter-time steps, and the representation of individual storages and water transfers would be necessary for local water resource planning to complement the broad-scale analysis.

[31] The classification of dry, normal, and wet weather is based on Robinson et al. [2005]. This implies that if water availability is below the 25 th percentile it is dry weather, if water availability is above the 75 th percentile it is wet weather, and the remaining distribution is normal weather. Given this classification, the average water availability associated with each type of weather can be estimated for the Murray River with the details provided in Appendix A. 
Table 2. Base-Case Parameter Values for Optimal Dynamic Water Allocation Model

\begin{tabular}{lcc}
\hline \multicolumn{1}{c}{ Variable Description } & Notation & Value \\
\hline Price coefficients & $\gamma$ & 2.647 \\
Price elasticity & $\varepsilon$ & 0.85 \\
Drought cost coefficient & $\alpha$ & 0.0037 \\
Drought cost elasticity & $\beta$ & 2.1 \\
Annual discount rate & $\rho$ & 0.05 \\
Inflows (in 10 ${ }^{3}$ GL) & $\Phi$ & $(4.68,9.93,21.5)$ \\
Weather correlation pattern & see Appendix A & see Appendix A \\
Thresholds for small, medium, & $\left(\Delta_{s}, \Delta_{m}, \Delta_{b}\right)$ & $(1.5,2.5,4.0)$ \\
$\quad$ and big floods & $\left(\Pi_{s}, \Pi_{m}, \Pi_{b}\right)$ & $(0,1,2)$ \\
Break periods for small, medium, & & \\
$\quad$ and big floods & $\delta$ & 1.1 \\
Conveyance & $\eta$ & 0.05 \\
Storage evaporation rate & & \\
\hline
\end{tabular}

\subsection{Other Parameters}

[32] Approximations of the water volumes that trigger floods and flood break times are derived from the following sources: Webster [2001], Goulburn Valley Environment Group [2007], Scott [1997], Pusey and Arthington [2003], and Baldwin [2008]. The conveyance water is taken from Campbell [2008], Grafton and Jiang [2010], and Ganf et al. [2010]. The flood break times are assumed to be 0,1 , and 2 years for small, medium, and big floods, respectively. All numerical values used to calibrate the model are reported in Table 2.

\section{Model Results}

[33] We solve the stochastic dynamic programming problem given by expression (11) to determine how much water should be released to the environment and also allocated to irrigation in each period based on the current state variables. These allocations will, in general, vary over time and depend on the realization of the uncertain weather (dry, normal, or wet). The model results are compared to the actual water allocations that occurred on the Murray River from 2001 to 2009, a period coincident with a major drought.

\subsection{Baseline Scenario and Principles in Water Allocation}

[34] When irrigation volumes are reduced by a given percentage, net profits decline by a smaller proportion because of the concavity of irrigation net profits and the existence of water markets along the Murray River. Water markets allow water to be transferred from low to higher value uses [National Water Commission, 2009]. Consequently, if overall diversions by irrigators are reduced, the least profitable irrigation activities are reduced first. Without water markets the loss in profits from reduced diversions to irrigation would be much larger and the dynamic water allocation model would allocate correspondingly less water for the environment.

[35] Figures 3-5 show the optimal irrigation volume is generally less than the actual volume except for the period immediately following a relatively wet year in 2002 and in 2005. Cumulatively, putting aside the base year 2001, from 2002 to 2009 the actual total irrigation volume is $24.73 \mathrm{TL}$ while the optimal allocation to irrigated agriculture is 22.12 TL (see Table 4), which represents a reduction of $2.61 \mathrm{TL}$ (approximately 10\%). As a result of this reduction in the irrigation volume, the net aggregate profits (discounted to the base year 2001) are reduced from 11.52 to 11.19 billion USD (see Figure 5) by about USD 330 million, or approximately $2.8 \%$. (We convert all Australian dollars to U.S. dollars at the exchange rate of \$A $1.00=$ USD 0.90.) The nonproportional relationship between the percentage reduction in the irrigation volume and the net profit captures the fact that any reduction in the water available for irrigation is incurred first by the less profitable irrigation activities.

[36] Figures 6-8 illustrate the benefits from environmental releases. In the optimal allocation two artificial floods are created in 2004 and 2006 that keep drought costs at relatively low levels, as shown in Figure 6. Figures 7 and 8, respectively, present the annual and cumulative drought

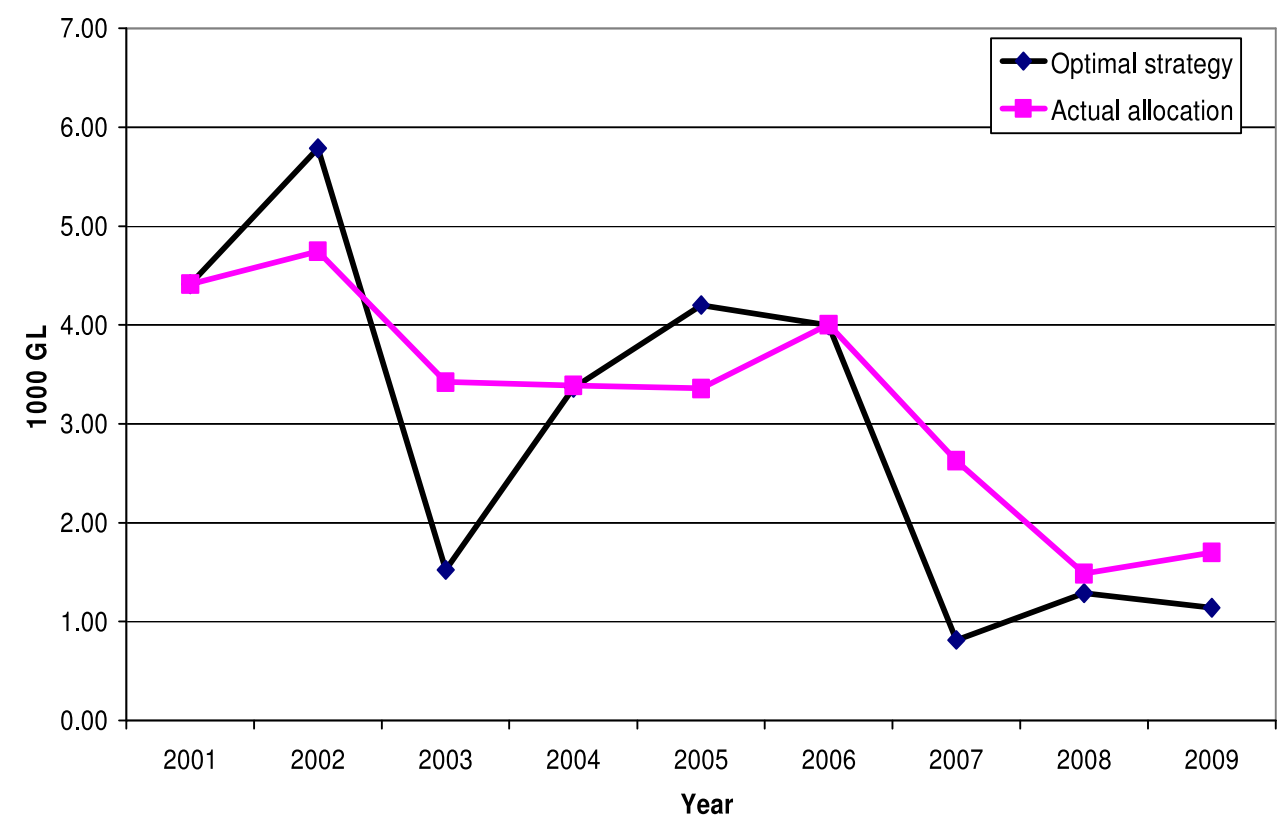

Figure 3. Annual irrigation extractions (actual versus optimal). 


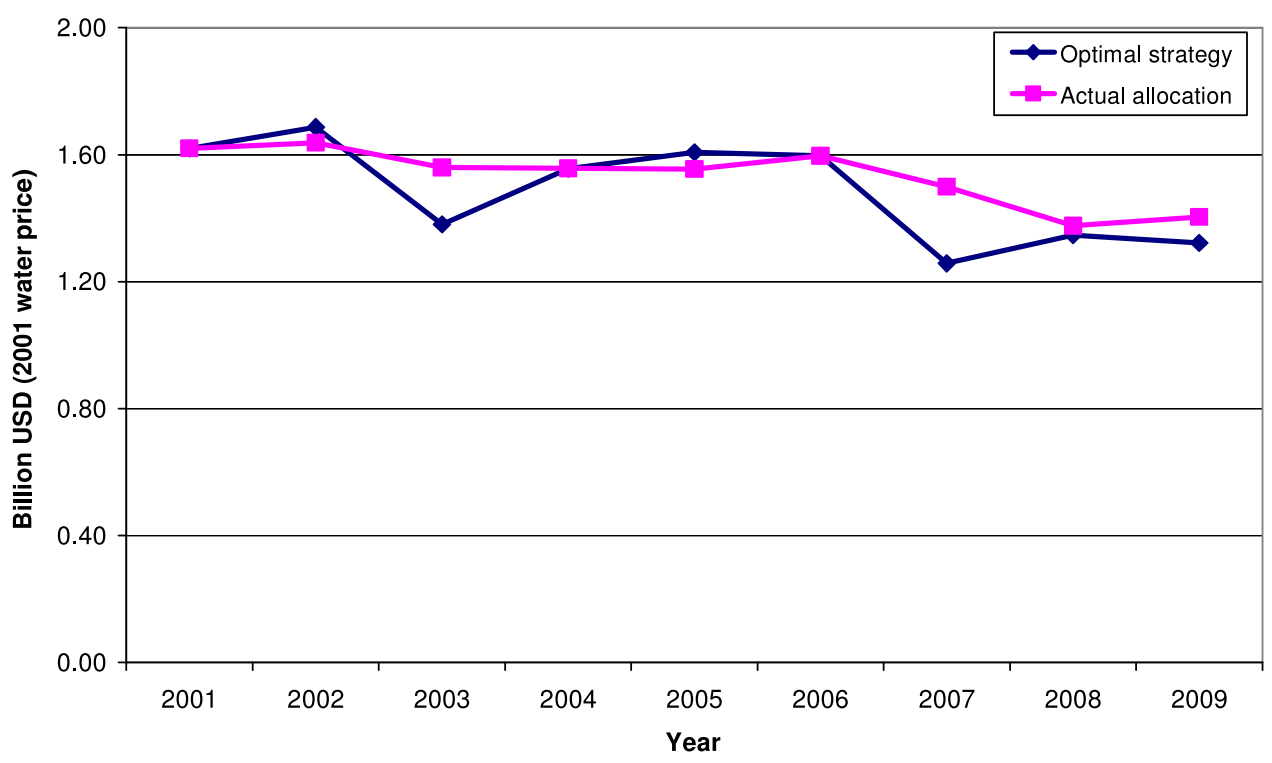

Figure 4. Annual net profits in irrigated agriculture (actual versus optimal).

costs (discounted to the base year 2001 and accumulated from 2001 to 2009) from optimal and actual water allocations. The optimal water allocation reduces the cumulative drought cost calculated to be over USD 1 billion without any floods over the period. By contrast, the two floods created under the optimal water allocation keep the cumulative drought costs at less than USD 200 million, generating gains of around USD 800 million. Comparing the reduction in the irrigation profit and the saving from the environment, the net gain of the optimal water allocation from the actual allocation during the 2001-2009 period is USD 558 million (in 2001 prices).

\subsection{Response Function}

[37] The optimal water allocation crucially depends on the realization of uncertain weather and specific annual inflows. In general, a higher level of disposable water volumes (i.e., the current storage and the current water recharging inflow) and/or a longer drought period will trigger the decision to make a flood. This is because whether to create a flood or a pulse effect depends on the amount of water available, and the current cost if there is a damaging drought.

[38] Figure 9 illustrates the optimal environmental releases in dry years with different disposable water quantities and drought lengths. Three years after a flood break period (the drought length is 3 years), a medium flood should be made only if $13 \mathrm{TL}$ of water is available (all storage facilities are full). If the disposable water that is available is $9 \mathrm{TL}$, a small flood should be created. If only smaller volumes of water are available, it is optimal to wait for another year before a small flood is created.

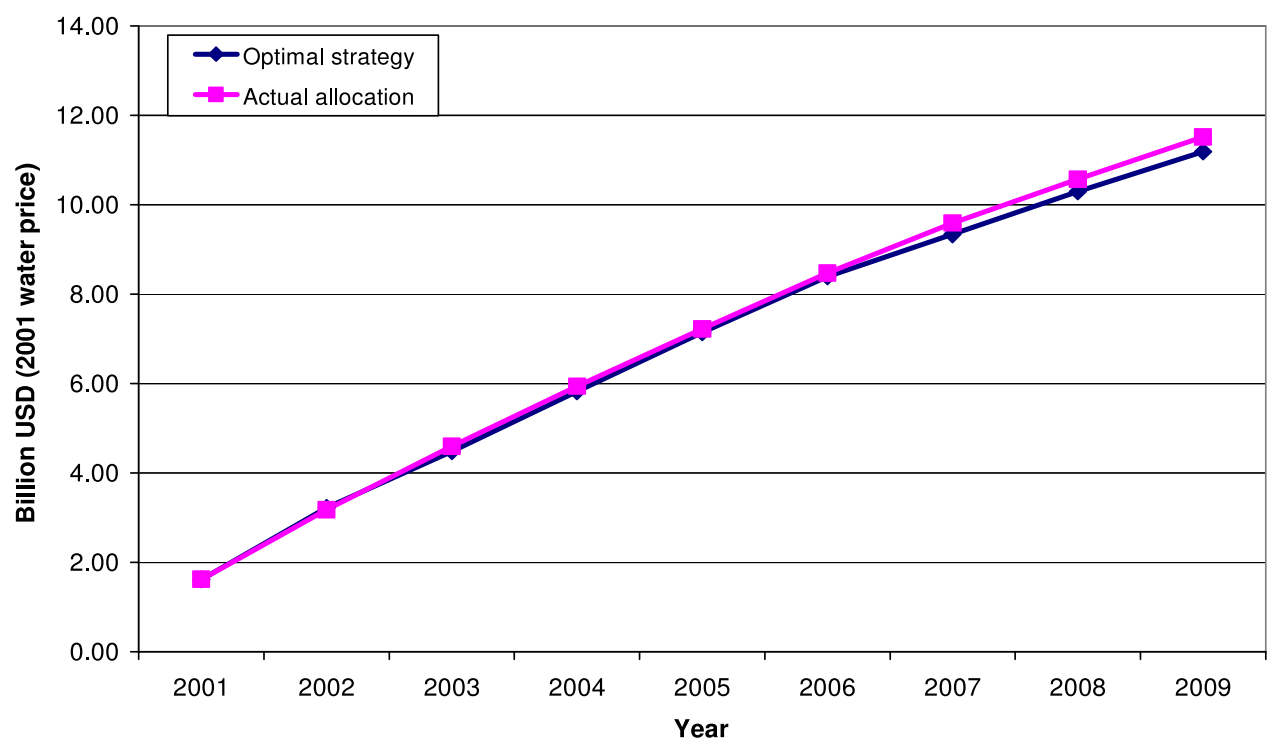

Figure 5. Cumulative net profits in irrigated agriculture (actual versus optimal). 


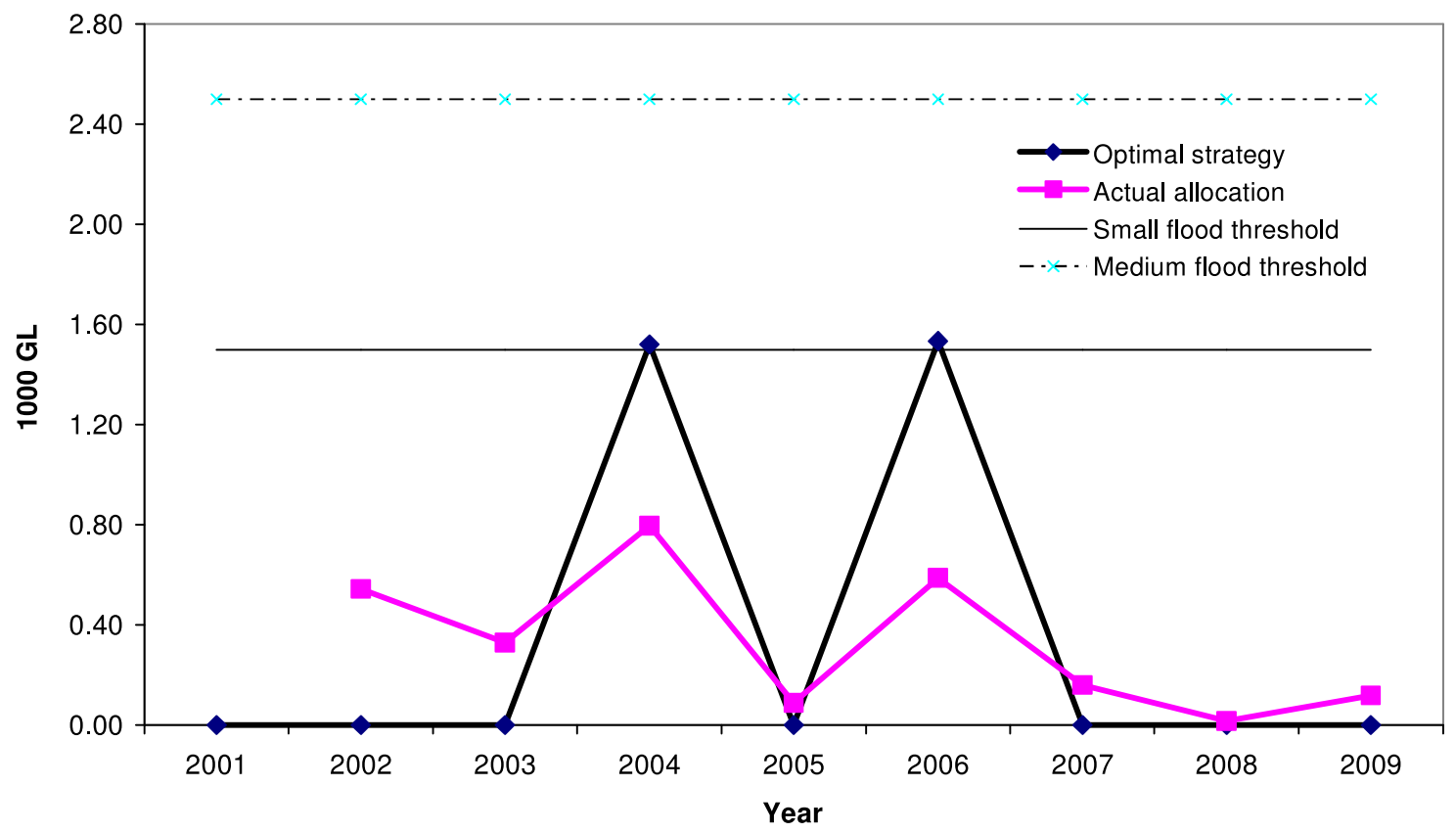

Figure 6. Environmental releases (actual versus optimal). The actual environment allocations from 2002 to 2007 are calculated as the residual water quantity of inflow net conveyance, consumptive diversion, and change in storages [MDBC, 2004, 2005, 2006, 2007, 2008]. For actual environment allocation in 2008 and 2009, see MDBC [2008] and Murray-Darling Basin Authority [2010].

\subsection{Pulse Effects}

[39] The analysis of 2001-2009 actual water allocations and the hypothetical response function emphasize an important qualitative result of the optimal strategy, the pulse effect. This effect implies that floods will be created in some years and no water beyond conveyance or base flows is released to the environment in other years. If annual inflows are always realized at the mean, the flood or pulse events would always be created in a regular manner. We illustrate this point in Figure 10 for dry and normal weather sequences where small or medium floods are created every 3 years. The reason for the pulse effect is that the environmental release will be postponed until a drought lasts for a certain period of time and becomes too damaging. In practice, the flood cycle may not be as regular because the period between two planned floods will vary depending on the actual realization of the weather and the water inflows, both of which are random variables.

\subsection{Sensitivity of the Price Elasticity Parameter}

[40] The price elasticity for irrigation water measures the sensitivity of the net profits associated with irrigated agriculture when irrigation diversions are reduced. The larger the price elasticity in the inverse demand $(\varepsilon)$ for a given

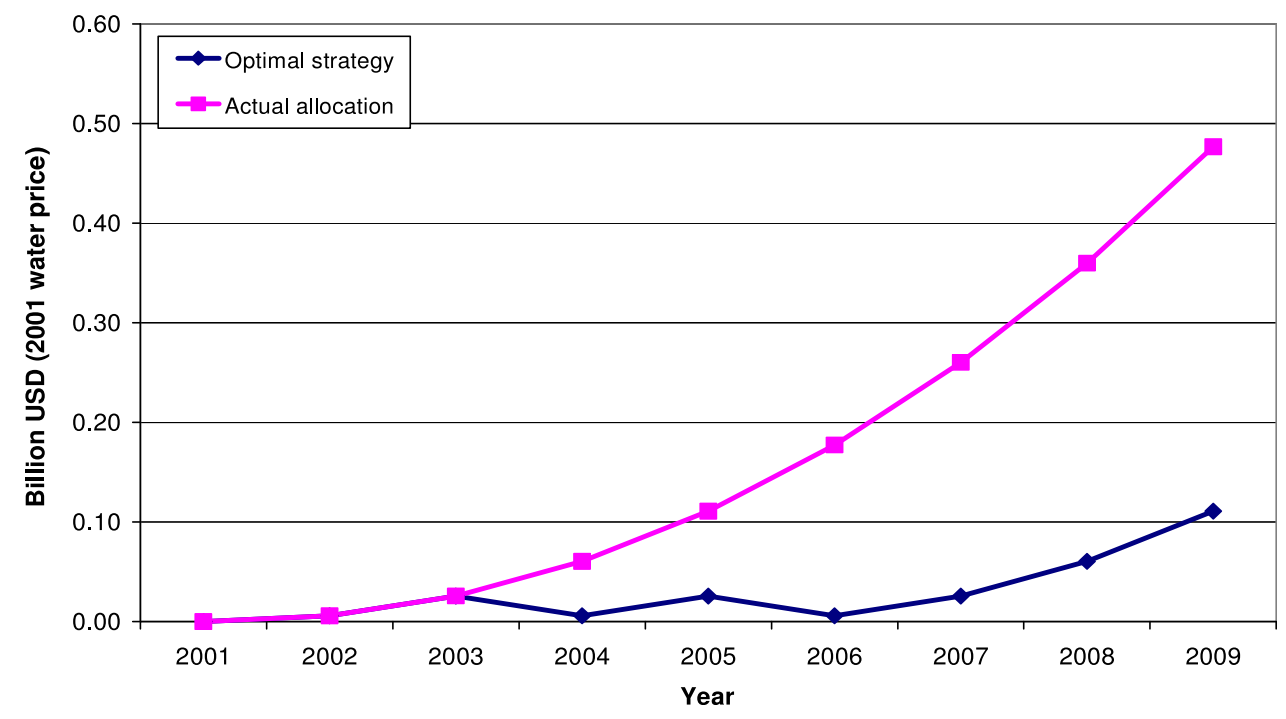

Figure 7. Annual drought costs to the environment (actual versus optimal). 


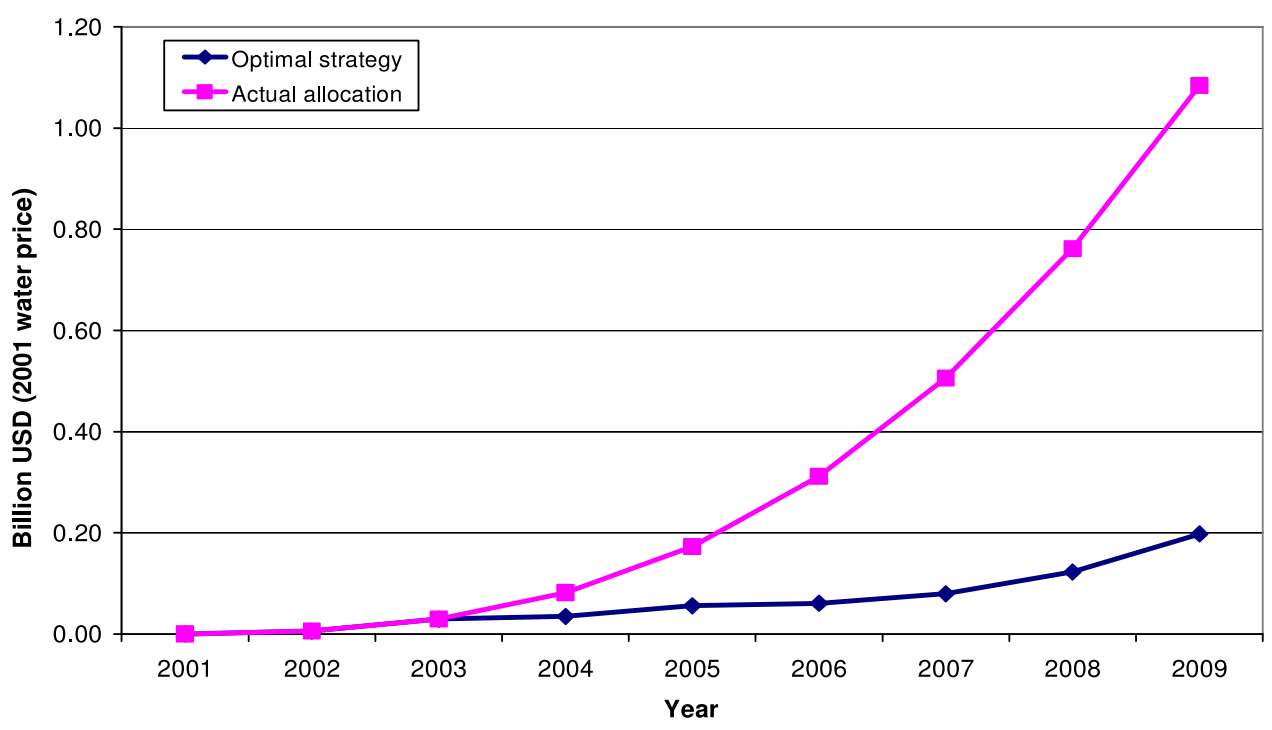

Figure 8. Cumulative drought costs on the environment (actual versus optimal).

reduction in irrigation extractions the greater will be the increase in the price of water used in irrigation, and the more modest will be the decline in the net profit defined by (8). We calculate the optimal allocation strategies for different price elasticities and the gain from the optimal water allocation relative to actual strategies. These results are presented in Table 3. Smaller elasticities generate larger net profit reductions from a given reduction in irrigation extractions and, thus, smaller gains from reallocating water from irrigated agriculture to environmental flows, and less frequent or smaller floods. For instance, when $\varepsilon=0.60$ the gains from reallocation from irrigation to environmental flows are some USD 300 million, but when $\varepsilon=0.90$ the gains from reallocation are over USD 600 million.

\subsection{Sensitivity of the Drought Cost Parameters}

[41] In addition to the price elasticity, the drought cost coefficient $(\alpha)$ and the drought cost elasticity $(\beta)$ have an important influence on the optimal water allocation. A higher value for the drought cost coefficient and/or the drought cost elasticity implies that the drought cost will increase more quickly with respect to the drought length. The base-case parameters are estimated from the drought lengths (years) that would make the drought cost equal to $50 \%$ and $100 \%$ of the present value cumulative irrigation

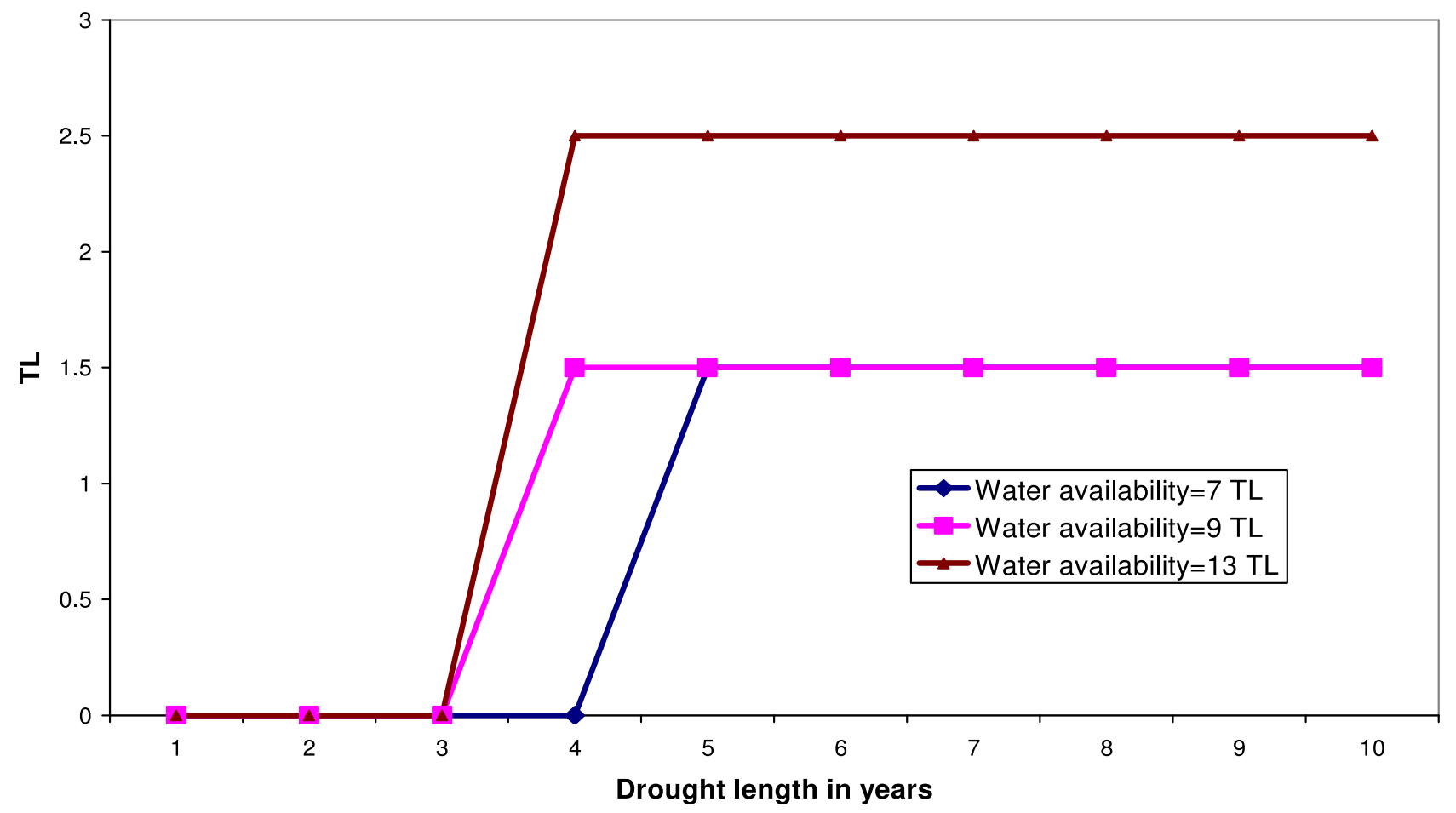

Figure 9. Optimal environmental releases with different water availability. 


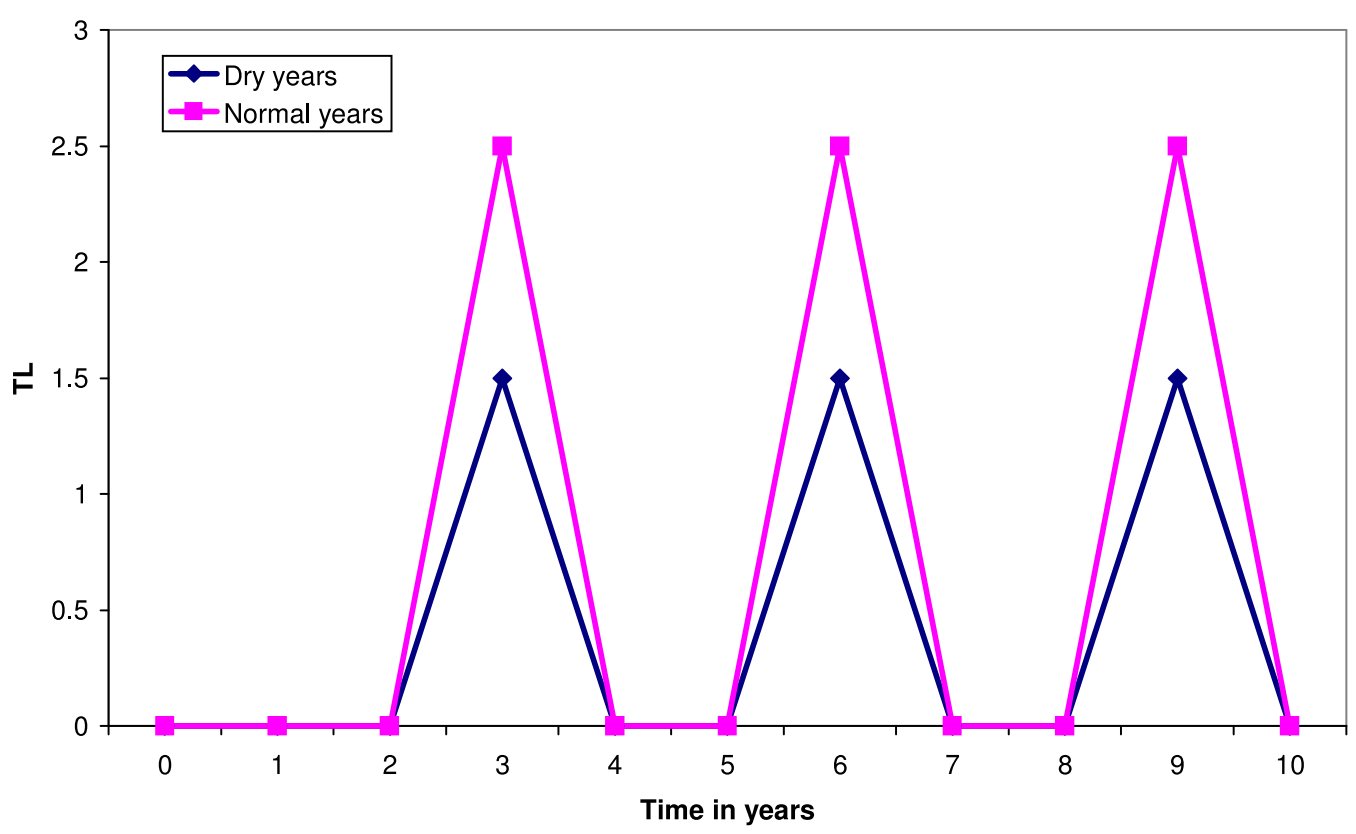

Figure 10. Optimal environmental releases with constant inflows (dry and normal).

net profits from water use. The base-case assumptions place an upper bound on environmental costs and are proirrigation because it is possible that the drought costs to the environment may exceed the net profits in irrigation. (Morrison et al. [2010] find that the total willingness to pay to improve the quality of the Coorong, at the Murray Mouth, that would increase the frequency of water bird breeding from every 10 years to every 7 years, raise native fish populations from $30 \%$ to $40 \%$ of original levels, and increase the area of healthy native vegetation from $50 \%$ to $60 \%$, is in excess of USD 1 billion per year for 10 years.) The basecase parameters indicate that a modest reallocation of 2.62 TL from irrigated agriculture to environmental flows, coupled with a pulse environmental flow regime, would have generated net social returns of USD 558 million over the period.

[42] We calculate the optimal strategies under various assumptions on the drought cost parameters and report the results in Table 4. Different parameter values generate different drought costs. If drought costs equal $100 \%$ of net profits in irrigated agriculture after 30 years, the net social return from pursuing an optimal water allocation is a little less than half a billion USD. If the drought cost reaches $100 \%$ of net profits in irrigated agriculture after 15 years the social return is much higher, or some 3 billion USD.

[43] Depending on the values of the drought cost parameters $(\alpha$ and $\beta)$, it is possible that the optimal dynamic water allocation mimics environmentally based watering rules designed to achieve a "moderate" probability of a healthy working river where environmental flows are about half of natural flows, or a "high" probability of a healthy working river where environmental flows are twothirds or greater of natural flows [Jones et al., 2002, p. 6]. An optimal water allocation achieves a moderate probability of a healthy working river if $\varepsilon=0.85$ and the cumulative costs to the environment of no floods equals $50 \%$ of cumulative net profits from irrigated agriculture after 12 years, and $100 \%$ of cumulative net profits after 20 years. An optimal water allocation approximates a high probability of a healthy working river with $\varepsilon=0.90$ and if the cumulative costs to the environment of no floods equals $50 \%$ of cumulative net profits from irrigated agriculture after 7 years, and $100 \%$ of cumulative net profits after 10 years.

\section{Concluding Remarks}

[44] We develop a general and optimal dynamic water allocation model to help answer the question of how to allocate scarce surface water among competing uses while accounting for trade-offs and weather. The model accounts for stochasticity in weather related events, optimizes the trade-off in water allocation between irrigated agriculture and environmental flows, and can be applied to any twouse surface water trade-off at a basin scale. Thus, the

Table 3. Sensitivity Analysis of Price Elasticity of Irrigation Water on Optimal Water Allocation to the Environment, Murray River 2002-2009

\begin{tabular}{|c|c|c|c|}
\hline Price Elasticity & Net Gain in USD (millions) & Flood Cycle in Dry Years & Flood Cycle in Normal Years \\
\hline$\varepsilon=0.60$ & 300 & Small floods every 4 years & Small floods every 2 years \\
\hline$\varepsilon=0.75$ & 486 & Small floods every 4 years & Small floods every 2 years \\
\hline$\varepsilon=0.85$ & 558 & Small floods every 3 years & Medium floods every 3 years \\
\hline$\varepsilon=0.90$ & 612 & Small floods every 3 years & Medium floods every 2 years \\
\hline
\end{tabular}


Table 4. Optimal Water Allocation (Teraliters) and Sensitivity Analysis of Drought Cost Parameters, Murray River, 2002-2009

\begin{tabular}{|c|c|c|c|c|c|c|c|c|c|c|c|}
\hline \multirow[b]{3}{*}{ Year } & \multirow{3}{*}{$\begin{array}{l}\text { Conveyance } \\
\text { Water }(\delta)\end{array}$} & \multirow{2}{*}{\multicolumn{2}{|c|}{$\begin{array}{l}\text { Actual Water } \\
\text { Allocation }^{\mathrm{b}}\end{array}$}} & \multirow{2}{*}{\multicolumn{2}{|c|}{$\begin{array}{l}\text { Optimal Water } \\
\text { Allocation } \\
\text { (Base Case): } \\
\varepsilon=0.85 \\
a=20 \\
b=30\end{array}$}} & \multicolumn{6}{|c|}{$\begin{array}{l}\text { Sensitivity Analysis of Optimal } \\
\text { Water Allocation }(\varepsilon=0.85)\end{array}$} \\
\hline & & & & & & \multicolumn{2}{|c|}{$a=15, b=25$} & \multicolumn{2}{|c|}{$a=12, b=20$} & \multicolumn{2}{|c|}{$a=10, b=15$} \\
\hline & & $e$ & $i$ & $e$ & $i$ & $e$ & $i$ & $e$ & $i$ & $e$ & $i$ \\
\hline 2002 & 1.10 & 0.54 & 4.74 & 0.00 & 5.79 & 2.53 & 3.41 & 2.53 & 3.41 & 2.53 & 3.41 \\
\hline 2003 & 1.10 & 0.33 & 3.42 & 0.00 & 1.52 & 0.00 & 1.46 & 0.00 & 1.46 & 0.00 & 1.46 \\
\hline 2004 & 1.10 & 0.80 & 3.39 & 1.52 & 3.37 & 0.00 & 4.82 & 2.52 & 2.30 & 2.52 & 2.30 \\
\hline 2005 & 1.10 & 0.09 & 3.36 & 0.00 & 4.20 & 1.50 & 2.69 & 0.00 & 4.19 & 0.00 & 4.19 \\
\hline 2006 & 1.10 & 0.59 & 4.00 & 1.53 & 4.00 & 2.53 & 3.03 & 2.53 & 3.03 & 2.53 & 3.03 \\
\hline 2007 & 1.10 & 0.16 & 2.63 & 0.00 & 0.81 & 0.00 & 0.80 & 0.00 & 0.80 & 0.00 & 0.80 \\
\hline 2008 & 1.10 & 0.02 & 1.49 & 0.00 & 1.29 & 0.00 & 1.29 & 0.00 & 1.29 & 0.00 & 1.29 \\
\hline 2009 & 1.10 & 0.12 & 1.70 & 0.00 & 1.14 & 0.00 & 1.13 & 0.00 & 1.13 & 0.00 & 1.13 \\
\hline Total & 8.80 & 2.64 & 24.73 & 3.06 & 22.12 & 6.56 & 18.63 & 7.59 & 17.61 & 7.59 & 17.61 \\
\hline $\begin{array}{l}\text { Environmental } \\
\text { releases/diversions }\end{array}$ & & & 0.11 & & 0.14 & & 0.35 & & 0.43 & & 0.43 \\
\hline $\begin{array}{l}\text { Gain optimal } \\
\text { versus actual } \\
\text { allocation (2001, in } \\
\text { billions of USD) }\end{array}$ & & & & & 0.558 & & 1.539 & & 2.403 & & 3.168 \\
\hline
\end{tabular}

${ }^{a}$ Here, $a$ is number of years until the cumulative environmental costs of drought equals $50 \%$ of the cumulative net present value of net profits in irrigated agriculture, and $b$ is number of years until the cumulative environmental costs of drought equals $100 \%$ of the cumulative net present value of net profits in irrigated agriculture.

${ }^{\mathrm{b}}$ Sources for actual water allocation: $M D B C[2004,2005,2006,2007,2008]$ and $M D B A[2010]$.

model operationalizes many of the key factors that decide how water should be allocated across competing uses and in situ uses.

[45] Our model provides decision makers with a tool to assess the trade-offs between different allocations with different parameter values. This is accomplished by specifying a convex relationship between drought length and environmental damages, and a concave relationship between water diversions and net profits from irrigated agriculture. The underlying parameters of the use and in situ uses for water can, and should, be modified by decision makers to undertake sensitivity analyses of the optimal water allocation to changes in parameter values.

[46] We calibrate the model to the Murray River scenario to compare actual with optimal water allocations. Concavity in net profits in irrigated agriculture associated with water extractions, coupled with a competitive water markets, reduce the costs of increased environmental flows as reductions in irrigation diversions would come first from low profit activities. Our results show that, contrary to current practice, small or medium floods should be created every 1 or 2 years to generate pulse effects in terms of environmental flows. The qualitative nature of the pulse effect is robust to changes in the underlying parameters used in the model. If a periodic pulse strategy had been implemented over the past decade along the Murray River, the model calculates that this would have generated net societal benefits of between half a billion and some 3 billion USD in net present value terms, depending on parameter values.

[47] Current water planning on the Murray River substantially reduces the frequencies of medium and small floods when inflows are below average. Below normal inflows also increase the trade-offs between water extractions and environmental flows. It is in these dry-to-normal inflow periods that the dynamic water allocation model is of greatest value in terms of improving water allocation decisions and increasing net benefits to society. Overall, the results show that the optimal dynamic water allocation model is an important tool to water planners to (1) better understand the trade-offs between competing uses and (2) optimize water allocation decisions. However, our model is not able to determine the timing and size of environmental releases to any specific sites or ecosystems because of the abstract representation of the hydrological and ecological systems. The calculation of releases to specific assets requires more finely detailed models that better capture the spatial information of the network structure of tributaries and ecological systems.

\section{Appendix A}

\section{A1. Estimation of Inflow Means}

[48] Using the data on total inflows from 1892 to 2006, we calculate the seasonal yearly inflow (a seasonal year starting in July and ending in June). The average yearly inflows associated to each type of weather can be estimated in Table A1.

[49] Given the estimate of $\ln$ (inflows), the mean of the water availability associated to each weather type can be estimated, such that $\Phi^{d} \simeq e^{8.407+(1 / 2) 0.2882}=4668(\mathrm{GL}) ; \Phi^{n}$ $\simeq e^{9.162+(1 / 2) 0.2882}=9930(\mathrm{GL}) ; \quad \Phi^{w} \simeq e^{9.934+(1 / 2) 0.2882}$ $=21,491(\mathrm{GL})$.

Table A1. Estimated Water Availability

\begin{tabular}{cccc}
\hline Independent Variables & Coefficients & SE & $t$ Value \\
\hline Dry weather & 8.407 & 0.060 & 139.23 \\
Normal weather & 9.162 & 0.038 & 238.83 \\
Wet weather & 9.934 & 0.048 & 203.52 \\
Dependent variable & Sample size & Overall fitness & SE \\
ln(inflows) & $N=115$ & $R^{2}=0.78$ & 0.288 \\
\hline
\end{tabular}


Table A2. Estimated Weather Serial Correlation

\begin{tabular}{|c|c|c|c|c|c|c|c|c|c|c|c|}
\hline \multicolumn{4}{|c|}{ Probability of Dry Weather $W_{t+1}=d$} & \multicolumn{4}{|c|}{ Probability of Normal Weather $W_{t+1}=n$} & \multicolumn{4}{|c|}{ Probability of Wet Weather $W_{t+1}=w$} \\
\hline$W$ & $P=W_{d}$ & $P=W_{n}$ & $P=W_{w}$ & $W$ & $P=W_{d}$ & $P=W_{n}$ & $P=W_{w}$ & $W$ & $P=W_{d}$ & $P=W_{n}$ & $P=W_{n}$ \\
\hline$W_{d}$ & 0.33 & 0.43 & 0 & $W_{d}$ & 0.67 & 0.50 & 0.67 & $W_{d}$ & 0 & 0.073 & 0.33 \\
\hline$W_{n}$ & 0.25 & 0.21 & 0.37 & $W_{n}$ & 0.56 & 0.58 & 0.55 & $W_{n}$ & 0.19 & 0.31 & 0.09 \\
\hline$W_{w}$ & 0 & 0.31 & 0.17 & $W_{w}$ & 0.67 & 0.23 & 0.50 & $W_{w}$ & 0.33 & 0.46 & 0.33 \\
\hline
\end{tabular}

\section{A2. Weather Correlation}

[50] We estimate the weather correlation using the formula

$$
\begin{aligned}
& \operatorname{prob}\left(W_{t+1}=i \mid W_{t}=j, W_{t-1}=k\right) \\
& \quad=\frac{\text { frequency }\left(W_{t+1}=i, W_{t}=j, W_{t-1}=k\right)}{\text { frequency }\left(W_{t}=j, W_{t-1}=k\right)},
\end{aligned}
$$

where $i, j, k=\{d, n, w\}$.

[51] Using the weather classification by Robinson et al. [2005], the weather correlation can be represented in Table A2.

\section{References}

Arthington, A., R. J. Naiman, M. E. McClain, and C. Nilsson (2010), Preserving the biodiversity and ecological services of rivers: New challenges and research opportunities, Freshwater Biol. 55(1), 1-16.

Bacon, P. E., C. Sone, D. Binns, D. Leslie, and J. Edwards (1993), Relationship between water availability and Eucalyptus camaldulensis growth in a riparian forest, J. Hydrol., 150(2-4), 541-561.

Baldwin, C. L. (2008), Integrating values and interests in water planning using a consensus-building approach, Ph.D. thesis, University of Queensland, Australia.

Baldwin, D. S. (1999), DOM and dissolved P leached from fresh and 'terrestrially'-aged river Red Gum Leaves - Implications for assessing riverfloodplain interactions, Freshwater Biol., 41, 675-685.

Bellman, R. (1957), Dynamic Programming, Princeton Univ. Press, Princeton, N.J., republished 2003, Dover, New York.

Brennan, D. (2004), Price formation on the Northern Victorian water exchange, mimeograph.

Bunn, S. E., and A. H. Arthington (2002), Basic principles and ecological consequences of altered flow regimes for aquatic biodiversity, Environ. Manage., 30, 492-507.

Campbell, B. (2008), Unprecedented drought: Climate change and the Murray-Darling Basin, mimeograph.

CSIRO (2007), Water availability in the GwyDir. A report to the Australian government, 148 pp., Murray-Darling Basin Sustainable Proj., Canberra.

CSIRO (2008), Water availability in the Murray-Darling Basin. A report to the Australian Government, 68 pp., Murray-Darling Basin Sustainable Proj., Canberra.

Dai, A., et al. (2009), Changes in continental freshwater discharge from 1948 to 2004 , J. Clim., 22(10), 2773-2792.

Döll, P., et al. (2009), Global-scale analysis of river flow alterations due to water withdrawals and reservoirs, Hydrol. Earth Syst. Sci., 13(12), 24132432 .

Dudgeon, D., et al. (2006), Freshwater biodiversity: Importance, threats, status and conservation challenges, Biol. Rev., 81, 163-182.

Ganf, G., S. White, and R. Oliver (2010), Allocating water to the wetlands of the Murray Valley to maximize aquatic plant species diversity, in Ecosystem Response Modelling in the Murray-Darling Basin, edited by N. Saintilan and I. Overton, pp. 279-299, CSIRO Pub., Canberra.

Goulburn Valley Environment Group (2007), Redgum special edition, newsletter, Shepparton, Vic, Australia.

Grafton, Q., and Q. Jiang (2010), Economics of water recovery in the Murray-Darling Basin, CWEEP paper, Aust. Natl. Univ., Acton, ACT, Australia.
Haddeland, I., et al. (2007), Hydrologic effects of land and water management in North America and Asia: 1700-1992, Hydrol. Earth Syst. Sci. 11(2), 1035-1045.

Harris, J. H., and P. C. Gehrke (1994), Development of predictive models linking fish population recruitment with streamflow, in Australian Society for Fish Biology Workshop, Perth, edited by D. A. Hancock, pp. 195197, Australian Society for Fish Biology, Sydney.

Jenkins, K. M., and A. J. Boulton (1998), Community dynamics of invertebrates emerging from reflooded lake sediments: flood pulse and aeolian influences, Int. J. Ecol. Environ. Sci., 24, 179-192.

Jones, G., T. Hillman, R. Kingsford, T. McMahon, K. Walker, A. Arthington, J. Whittington, and S. Cartwright (2002), Independent report of the expert reference panel on environmental flows and water quality requirements for the River Murray system, Coop. Res. Cent. for Freshwater Ecol., Canberra.

Junk, W. J., P. B. Bayley, and R. E. Sparks (1989), The flood pulse concept in river floodplain systems, Spec. Publ. Can. J. Fish. Aquat. Sci., 106, $110-127$.

Kingsford, R. (2010), Environmental flows - How much and how do we manage them?, in Making Decisions About Environmental Water Allocations, Aust. Farm Inst., Surry Hulls, NSW, Australia.

Kingsford, R. T., and K. M. Auld (2005), Waterbird breeding and environmental flow management in the Macquarie Marshes, Arid Australia, River Res. Appl., 21(2-3), 187-200.

Lehner, B., and P. Döll (2004), Development and validation of a global database of lakes, reservoirs and wetlands, J. Hydrol., 296, 1-22.

Lehner, B., et al. (2006), Estimating the impact of global change on flood and drought risks in Europe: A continental, integrated analysis, Clim. Change, 75(3), 273-299.

Lintermans, M. (2007), Fishes of the Murray-Darling Basin: An introductory guide, MDBC Publication No. 10/07.

Meyer, W. (2005), The irrigation industry in the Murray and Murrumbidgee Basins, mimeograph.

Morrison, M., D. Hatton-MacDonald, K. Boyle, and J. Rose (2010), Ecological values for a major river system at risk: Australia's MurrayDarling River system, mimeograph.

Murray-Darling Basin Authority (MDBA) (2010), Water Audit Monitoring Report 2008-2009, Report of the Murray-Darling Basin Authority on the Cap on Diversions, Canberra.

Murray-Darling Basin Commission (MDBC) (2003), Preliminary investigations into observed river red gum decline along the River Murray below Euston, Tech. Rep. 03/03, Canberra

Murray-Darling Basin Commission (MDBC) (2004), Annual report 2003 2004, Canberra.

Murray-Darling Basin Commission (MDBC) (2005), Annual report 20042005, Canberra.

Murray-Darling Basin Commission (MDBC) (2006), Annual report 20052006, Canberra.

Murray-Darling Basin Commission (MDBC) (2007), Annual report 20062007, Canberra.

Murray-Darling Basin Commission (MDBC) (2008), Annual report $2007-$ 2008, Canberra.

National Land and Water Resources Audit (2001), Australian water resources assessment 2000, Canberra.

National Water Commission (2009), Australian Water Markets Report 2008-2009, Canberra.

Nilsson, C., et al. (2005), Regulation of the world's large river systems, Science, 308, 405-408.

Norris, R. H. (2010), How should Australia decide how much water in Australian rivers should be allocated to the environment, and how can the community be sure environmental water is being used efficiently?, in Making Decisions About Environmental Water Allocations, Aust. Farm Inst., Surry Hulls, NSW, Australia. 
Norris, R. H., P. Liston, N. Davies, F. Dyer, J. Coysh, F. Dyer, S. Linke, I. Prosser, and B. Young (2001), Snapshot of the Murray-Darling Basin River condition, 60 pp., Murray-Darling Basin Comm., Canberra.

Overton, I., D. Penton, and T. Doody (2010), Ecosystem response modelling in the River Murray, in Ecosystem Response Modelling in the River Murray, edited by N. Saintilan and I. Overton, pp. 243-263, CSIRO Publ., Canberra.

Poff, N. L., et al. (1997), The natural flow regime: A paradigm for river conservation and restoration, Science, 47, 769-784.

Poff, N. L., et al. (2007), Homogenization of regional river dynamics by dams and global biodiversity implications, Proc. Natl. Acad. Sci. U.S.A., $104,5732-5737$.

Poff, N. L., et al. (2010), Ecological responses to altered flow regimes: A literature review to inform the science and management of environmental flows, Freshwater Biol., 55(1), 195-204.

Postel, S. L., G. C. Daily, and P. R. Ehrlich (1996), Human appropriation of renewable fresh water, Science, 271, 785-788.

Pusey, B. J., and A. H. Arthington (2003), Flow restoration and protection in Australian rivers, River Res. Appl., 19, 1-19.

Richter, B. D., et al. (1997), How much water does a river need?, Freshwater Biol., 37, 231-249.

Robinson, D., S. Whitten, S. Khan, D. Collins, and J. Ward (2005), Modelling the economic benefit of cap and trade for irrigation salinity management, paper presented at 49th Annual Conference of the Australian Agricultural and Resource Economics Society, Coffs Harbour, NSW, Australia.
Scoccimarro, M., and D. Collins (2006), Natural resource buybacks and their use to secure environmental flows, Land and Water Aust., Canberra.

Scott, A. (1997), Relationships between waterbird ecology and river flows in the Murray-Darling Basin, Land and Water Tech. Rep. 5/97, Commonw. Sci. and Ind. Res. Organ., Collingwood, Vic, Australia.

Senate Standing Committee on Rural and Regional Affairs and Transport (2008), Water management in the Coorong and the Lower Lakes, Parliament of Aust., Canberra.

Thenkabail, P. S., et al. (2009), Global irrigated area map (GIAM), derived from remote sensing, for the end of the last millennium, Int. J. Remote Sensing, 30(14), 3679-3633.

Webster, R. (2001), Report of the inland rivers workshop, Land and Water Aust., Canberra.

Wilson, J., D. S. Baldwin, G. N. Rees, and B. P. Wilson (2010), Impact of flooding on microbial community structure, microbial activity and carbon dynamics in soil from a grazed and non-grazed floodplain forest, River Research and Applications doi:10.1002/rra.1255 Published online.

H. L. Chu, R. Q. Grafton, and T. Kompas, Crawford School of Economics and Government, Australian National University, Crawford Building (132), Lennox Crossing, Acton, ACT 0200, Australia. (quentin.grafton@anu.edu.au)

M. Stewardson, Department of Civil and Environmental Engineering, University of Melbourne, Level 4/ D402, Melbourne, Vic 3010, Australia. 